\title{
Targeting Faulty Bearings for an Ocean Turbine Dynamometer
}

\author{
Nicholas Waters ${ }^{1}$, Pierre-Philippe Beaujean ${ }^{2}$, and David J. Vendittis ${ }^{3}$ \\ ${ }^{1,2,3}$ Florida Atlantic University, 777 Glades Rd, Boca Raton, FL, 33431, USA \\ ncwaters1@gmail.com \\ pbeaujea@fau.edu (corresponding author) \\ dvendittis@aol.com
}

\begin{abstract}
A real-time, vibrations-based condition monitoring method used to detect, localize, and identify a faulty bearing in an ocean turbine electric motor is presented in this paper. The electric motor is installed in a dynamometer emulating the functions of the actual ocean turbine. High frequency modal analysis and power trending are combined to assess the operational health of the dynamometer's bearings across an array of accelerometers. Once a defect has been detected, envelope analysis is used to identify the exact bearing containing the defect. After a brief background on bearing fault detection, this paper introduces a simplified mathematical model of the bearing fault, followed with the signal processing approach used to detect, locate, and identify the fault. In the results section, effectiveness of the methods of bearing fault detection presented in this paper is demonstrated through processing data collected, first, from a controlled lathe setup and, second, from the dynamometer. By mounting a bearing containing a defect punched into its inner raceway to a lathe and placing an array of accelerometers along the length of lathe, the bearing fault is clearly detected, localized, and identified as an inner raceway defect. Through retroactively trending the data leading to the near-failure of one of the electric motors in the dynamometer, the authors identified a positive trend in energy levels for a specific frequency band present across the array of accelerometers and identify two bearings as possible sources of the fault.
\end{abstract}

\section{INTRODUCTION}

The Southeast National Marine Renewable Energy Center (SNMREC) is developing an Ocean Turbine (OT) that is capable of harnessing some of the energy contained in the Florida Current (Driscoll, 2008). Autonomy and minimal

Nicholas Waters et al. This is an open-access article distributed under the terms of the Creative Commons Attribution 3.0 United States License, which permits unrestricted use, distribution, and reproduction in any medium, provided the original author and source are credited. maintenance are of the utmost importance due to the high cost of accessing the OT for maintenance. By creating a self-diagnostic program capable of not only identifying the occurrence of a fault, but evaluating its severity and localizing it, said maintenance costs could be significantly reduced.

In addition to proper prognoses, early detection is critical due to the rapid deterioration of mechanisms under unexpected loads. Through vibrational analysis, which has been used to effectively detect and diagnose faults within other rotating machinery, one can achieve a level of awareness associated with the type of fault occurring, its location, and a relative level of severity. This information can then be used to determine whether maintenance is pertinent to prevent further damage to the system (Jayaswal, Wadhwani, \& Malchandani, 2008).

SNMREC has also developed a dynamometer to emulate some of the electrical and mechanical features of the OT. To do so, the dynamometer mimics the loads of the ocean current acting on the shaft connected to an electric motor/generator. A program, the Smart Vibrations Monitoring System (SVMS), was created by Mjit, Beaujean, and Vendittis (Mjit, Beaujean, \& Vendittis, 2011) for autonomous online monitoring of the dynamometer. SVMS is implemented using LabVIEW. The program uses such methods of fault detection and identification as Power Spectral Density (PSD) analysis, fractional octave analysis, kurtosis, cepstrum, and time waveform analysis (Mjit, 2009). The SVMS program was designed following the standards outlined by the International Standards Organization (ISO) on vibration condition monitoring (ISO, 2002; ISO, 2005) and, as such, the procedure for the high frequency analysis of the vibration signal outlined in this paper is carried out following the same guidelines.

The methods presented in this paper are implemented on an OT dynamometer, which operates on the same principal as wind turbines. Not unlike OTs, accessing wind turbines for maintenance can be difficult and costly. Thus, application of 
the methods outlined in this paper could greatly serve to minimize maintenance costs in the wind turbine sector of engineering. The methodology of detecting, localizing, and identifying is described in a manner to allow for straightforward application to wind turbines.

The terms detection, localization and identification are defined as follows: detection refers to detecting the presence of a bearing with a raceway defect as the defect forms, localization refers to localizing the faulty bearing location with respect to the position of the array of accelerometers placed along the length of the dynamometer, and identification refers to identifying the exact defective bearing and raceway.

The approach outlined in this paper relies on analysis of the high-frequency component of vibrations over an array of accelerometers placed along the length of the dynamometer. The vibrations (measured as an acceleration) caused by a defect in the inner or outer raceway of a given bearing is an amplitude-modulated signal (McFadden \& Smith, 1984). As each ball within a given bearing rolls over the defect, it causes a spike in the acceleration signal, which can be unidentifiable in the time waveform due to background noise and vibrations caused from other rotating components (gears, other bearings, etc.). This spike is modulated by the modes of vibration of the structure and the uneven load on the shaft (McFadden \& Smith, 1984).

Ideally, the resulting vibrations from the bearing defect alone would appear as an exponentially decreasing sinusoidal curve (Sheen, 2007). The difficulty in application of this faulty bearing detection method to the dynamometer mainly resides in identification of the faulty bearing, in the overall structural vibrations due to the multiple rotating components contributing to the vibration signature and slow rotational speeds leading to low signal to noise ratios. To do so, narrow-band envelope analysis is used to isolate several high-frequency modes of vibration (Sheen, 2004). This envelope analysis is performed on the vibration data collected across the array of accelerometers.

Bearing fault detection is carried out by trending the average power levels for specific frequency bands and for each accelerometer. In addition to trending average power levels, envelope power levels are computed across the array of accelerometers. An envelope power threshold is determined for each accelerometer's envelope power signal to further detect the presence of a faulty bearing.

Localization of the faulty bearing with respect to placement of each accelerometer is performed by comparing the average power levels computed over specific frequency bands for the entire array of accelerometers. The accelerometer with the highest average power level for a given frequency band is selected as the closest to the faulty bearing location, if the power level for this frequency band across the remaining accelerometers is significantly lower.
Identification of a bearing raceway defect is accomplished through demodulation of each accelerometer's signal about predetermined frequency bands, which allows for periodic impacts in the vibration signal to be clearly observed in the presence of a bearing with a raceway defect.

In the following section, this paper introduces a simplified mathematical model to provide a rudimentary understanding of the physics involved in the vibrations caused by ball bearings periodically coming in contact with a raceway defect. This model is also used to justify the assumption that the acquired vibrations due to bearing defects are the result of modulation. This model is also used to explain how the process of demodulation will be utilized to indicate which bearing is defective. Next, the signal processing approach used to detect, localize, and identify the fault is presented. Lastly, the approach is illustrated through a series of experimental data collected from a controlled lathe setup with a faulty bearing and from data collected from the dynamometer over the course of several weeks, leading up to a bearing failure.

\section{SCIENTIFIC APPROACH}

In this section, the authors introduce a simplified mathematical model describing the vibrations caused by a bearing with an inner raceway defect. This model relies on many assumptions that are summed up in the concluding section. This model is introduced solely to provide a very rudimentary understanding of the vibrations caused by the periodic impact of a ball coming in contact with a defect along the inner raceway of a bearing. It is also introduced to justify the use of the Hilbert transform demodulation technique used to identify the faulty bearing (Section 3.3).

As a first approach to modeling the vibrations induced by bearing raceway defects, we first consider the vibrations caused by a single ball bearing rolling over a single defect in the inner raceway. The forces acting on a single roller bearing are depicted in Figure 1.

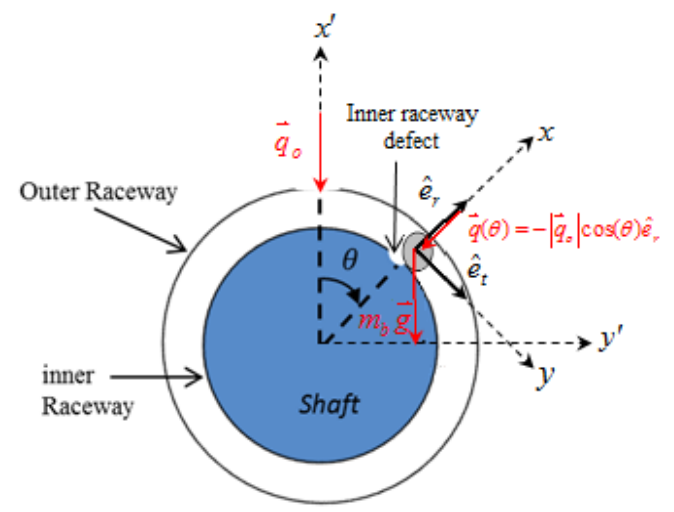

Figure 1. A shaft with a single ball bearing and a single defect on the inner raceway. 
The vertical force vector $\vec{q}_{0}$ represents the loading due to the mass of the shaft and bearing. is the angle measured from the vertical to the center of the defect. The vector $m_{b} \vec{g}$ represents the force due to gravity acting on the ball. The vector $\vec{q}()$ represents the x-component of the shaft and bearing loading acting on the ball as it passes over the inner raceway defect. The vectors $\hat{e}_{r}$ and $\hat{e}_{t}$ represent the radial and tangential unit vectors along the $\mathrm{x}$ and $\mathrm{y}$ axes, respectively. Through analysis of the equivalent lumped parameter model, the displacement for a single impact and mode of vibration $n$ is described by,

$$
x_{n}(t)=X_{n} e^{0, n n^{t}} \cos \left({ }_{d, n} t \quad{ }_{0, n}\right) u(t),
$$

where ${ }_{n}$ is the amplitude of the displacement for mode $n$ at time $t=0 . \quad{ }_{0, n}$ is the natural angular frequency. ${ }_{n}$ is the damping ratio (we assume the system is underdamped, so that $\left.{ }_{n}<<1\right) . \quad{ }_{d, n}$ is the damped natural angular frequency. $\quad 0, n \quad$ is the initial phase for this mode and $u(t)$ is a unit step function introduced into the equation, as this system is causal.

Assuming that every ball is identical and accounting for all the modes of vibration, multiple balls passing over the defect, and all the modes of vibration,

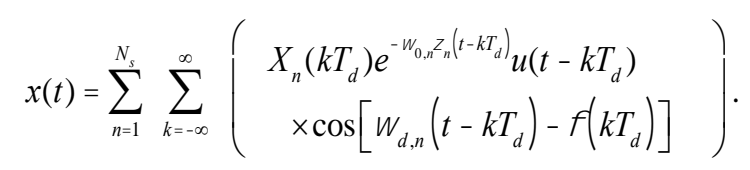

Here, $T_{d}$ is the period of rotation for a single ball, $K T_{d}$ is the time delay associated with the $k^{\text {th }}$ impact, and $N_{s}$ is the total number of modes of vibration. Differentiating Eq. (2) twice yields the equation that describes these vibrations in terms of acceleration.

$$
a(t)=\sum_{n=1}^{N_{s}} \sum_{k=-\infty}^{\infty}\left(\begin{array}{l}
A_{n, k} e^{-\omega_{0, n} \zeta_{n}\left(t-k T_{d}\right)} u\left(t-k T_{d}\right) \\
\times \cos \left[\omega_{d, n}\left(t-k T_{d}\right)-\phi_{n}^{\prime}\left(k T_{d}\right)\right]
\end{array}\right) .
$$

Equation (3) assumes that the accelerometer is placed directly over the source of vibrations. Since there is some signal loss in the vibrations as they propagate through the structure, new constants are introduced into Eq. (3) to account for this signal attenuation: $\tilde{H}_{C_{1}}, \tilde{H}_{T}, \tilde{H}_{C_{2}}$, and $\tilde{H}_{G}$ (Figure 2) represent the complex loss coefficients (or transfer functions) associated with the faulty bearing, first coupler, torque meter, second coupler, and gearbox, respectively. Note that these coefficients change with the natural angular frequency $0, n$.
Also, the symbol $a^{(1)}$ is used to denote the acceleration measured over the faulty bearing. $a^{\left(m_{i}\right)}$ represents the acceleration measured at a distance $d$ from the faulty bearing location.

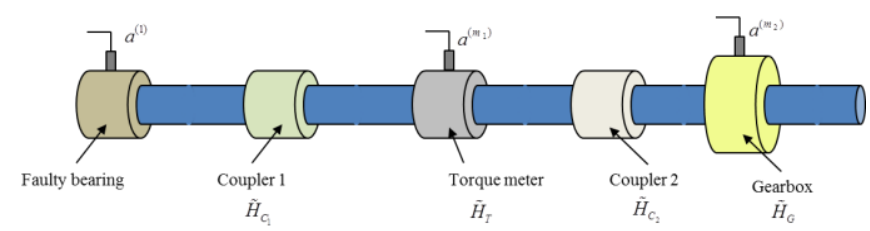

Figure 2. Simplified diagram of dynamometer components and associated loss coefficients.

For the acceleration measured at location $m_{i}$ on the dynamometer, $\beta^{\left(m_{i}\right)}$ represents the modal attenuation of the vibrations,

$$
{ }^{\left(m_{i}\right)}=e^{d, n n n_{d, n}^{\left(m_{i}\right)}} \tilde{H}^{\left(m_{i}\right)} .
$$

The parameter $\tilde{H}^{\left(m_{i}\right)}$ is defined according to Eq. (5),

$$
\tilde{H}^{\left(m_{i}\right)}=\left\{\begin{array}{ll}
\tilde{H}_{C_{1}} \cdot \tilde{H}_{T}, & \text { for } i=1 \\
\tilde{H}_{C_{1}} \cdot \tilde{H}_{T} \cdot \tilde{H}_{C_{2}} \cdot \tilde{H}_{G}, & \text { for } i=2
\end{array} .\right.
$$

Thus, accounting for signal attenuation due to the vibrations propagating through the structure, the acceleration at location $m_{i}$ is defined according to Eq. (6),

$$
\begin{aligned}
& a^{\left(m_{i}\right)}(t)=
\end{aligned}
$$

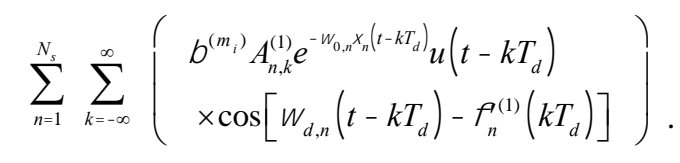

According to Eq. (6), the maximum observed acceleration for an accelerometer placed along the length of the dynamometer will be $\beta^{\left(m_{i}\right)} A_{n, k}{ }^{(1)}$. In order to determine which bearing is the source of the fault, demodulation of the acquired vibration signal is needed, which yields the envelope. The envelope of Eq. (6), is defined by the leading terms ${ }^{\left(m_{i}\right)} A_{n, k}^{(1)} e^{0, n n}\left(t k T_{d}\right) u\left(t \quad k T_{d}\right)$. From the envelope, the period between impacts can be determined, indicating which bearing is the source of the defect and whether or not it is within the inner or outer raceway of this bearing.

\section{SIGNAL PROCESSING}

The methodology used to detect, localize and identify bearing raceway faults are presented in section 4 . This methodology refers to several signal processing tools presented in this section. 


\subsection{PSD and Coherency}

We define $r^{\left(m_{i}\right)}(t)$ as output of accelerometer $m_{i}$ collected on a specific day. $r^{\left(m_{i}\right)}(t)$ represents the measurement equivalent of $a^{\left(m_{i}\right)}(t)$. We estimate the one-sided PSD of $r^{\left(m_{i}\right)}(t)$ as $\hat{G}_{r^{\left(m_{i}\right)}}(\quad)$ of the accelerometer output $r^{\left(m_{i}\right)}(t)$ through block averaging (Ifeachor \& Jervis, 2002), using Blackman windows and $50 \%$ overlap. The window length depends on the mode of vibration studied. $\hat{G}_{r^{\left(m_{i}\right)}}(\quad)$ is used to identify the bands that contain the natural angular frequencies described in the previous section.

The coherency estimate $\hat{r}_{r^{\left(m_{i}\right)_{r}^{\left(m_{j}\right)}}}(\quad)$ between the accelerometer outputs $r^{\left(m_{i}\right)}(t)$ and $r^{\left(m_{j}\right)}(t)$ indicates, as a function of the angular frequency, the fraction of power originating from the same physical process,

$$
\hat{\gamma}_{r^{\left(m_{i}\right) r^{\left(m_{j}\right)}}}(\omega)=\frac{\left|\hat{G}_{r^{\left(m_{i}\right)} r^{\left(m_{j}\right)}}(\omega)\right|^{2}}{\hat{G}_{r^{\left(m_{i}\right)}}(\omega) \hat{G}_{r^{\left(m_{j}\right)}}(\omega)} .
$$

$\hat{G}_{r^{\left(m_{i}\right) r^{\left(m_{j}\right)}}}(\omega)$ is the one-sided Cross Spectral Density (CSD) between the accelerometer outputs $r^{\left(m_{i}\right)}(t)$ and $r^{\left(m_{j}\right)}(t)$. The coherency is a dimensionless, frequency-dependent function that varies between 0 and 1 . For a specific angular frequency, a coherency value of 1 indicates that the vibration measured by the two accelerometers originates from the same physical process. $\quad \hat{G}_{r^{\left(m_{i}\right)} r^{\left(m_{j}\right)}}(\omega)$ is estimated with the same block averaging routine used for the PSD estimate.

\subsection{Power and Confidence Interval}

Power-trending is performed across the period of data acquisition (an illustration of the trending process is shown in section 4.2). For each day of data acquisition, the estimated power is calculated within every predetermined frequency band $\omega_{n}-\frac{\Delta \omega_{n}}{2} \leq \omega \leq \omega_{n}+\frac{\Delta \omega_{n}}{2}$ and for every accelerometer $m_{i}$,

$$
\hat{\Pi}_{m_{i}, n}=\int_{\omega_{n}-\frac{\Delta \omega_{n}}{2}}^{\omega_{n}+\frac{\Delta \omega_{n}}{2}} \hat{G}_{r^{\left(m_{i}\right)}}(\omega) d \omega .
$$

The confidence interval for a given confidence level for this power level estimate is calculated as shown in Eq. (9),

$$
1-\alpha=\operatorname{Pr}\left[\frac{v \overline{\hat{\prod}}_{m_{i}, n}}{\chi_{\frac{1-\alpha}{2}, v}^{2}} \leq \bar{\Pi}_{m_{i}, n} \leq \frac{v \overline{\hat{\prod}}_{m_{i}, n}}{\chi_{\frac{\alpha}{2}, v}^{2}}\right] .
$$

$\bar{\Pi}_{m_{i}, n}$ is the true average power across the same frequency band, $v=K_{w}^{\prime} Q$ is the degree of freedom ( $K_{w}^{\prime}$ is the window scaling factor; $Q$ is the number of block averages used to calculate $\hat{G}_{r^{\left(m_{i}\right)}}(\quad)$ ) and $\quad 2$ is the chi-square distribution).

\subsection{Envelope Analysis}

Theoretically, the complex envelope of the acceleration measured at accelerometer $m_{i}$ for mode $n$ is of the form shown in Eq. (10).

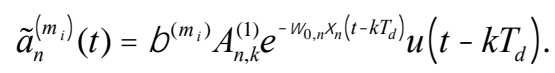

This complex envelope contains valuable information regarding the time signature of every mode as a function of the sensor location.

As mentioned earlier, the actual measured acceleration is $r^{\left(m_{i}\right)}(t)$. In this paper, the authors use the Hilbert transform of the measured acceleration to isolate the envelope of individual modes of vibration (demodulation of the signal). To do so, discrete Finite Impulse Response (FIR) filters are designed for every frequency band $\omega_{n}-\frac{\Delta \omega_{n}}{2} \leq \omega \leq \omega_{n}+\frac{\Delta \omega_{n}}{2}$. The discrete filter response for each band is labeled $h_{n}^{(R)}(t)$ (for the real part) and $h_{n}^{(I)}(t)$ (for the imaginary part). The estimated complex envelope at accelerometer $m_{i}$ for mode $n$, denoted by $\hat{a}_{n}^{\left(m_{i}\right)}(t)$, is the circular convolution between $\left(h_{n}^{(R)}(t)+j h_{n}^{(I)}(t)\right)$ and $r^{\left(m_{i}\right)}(t)$

$$
\hat{a}_{n}^{\left(m_{i}\right)}(t)=r^{\left(m_{i}\right)}(t) \quad\left(h_{n}^{(R)}(t)+j h_{n}^{(I)}(t)\right)
$$

\section{METHODOLOGY}

In this section, the staged approach to detecting, localizing, and identifying a growing raceway defect in a bearing is presented. It is important to note that these methods are performed under steady state conditions and at constant shaft rotational speeds for the dynamometer.

\subsection{Dynamometer's impulse response and frequency band selection}

The dynamometer's impulse response is measured to isolate the best frequency bands for the fault detection process. Here, the dynamometer does not rotate. Vibrations are produced across the array of accelerometers by striking the dynamometer with a calibrated hammer directly next to one of the accelerometers. The hammer strikes are administered such that vibrations are observed across the entire array of accelerometers without signal clipping. Also, the period between the hammer strikes is large enough to prevent 
signal overlap between vibrations due to subsequent impacts.

As the dynamometer is struck, structural resonances are excited, leading to peaks in the PSD of the vibration signals acquired by the accelerometers (estimated as described in section 3.2). In order to maximize the signal-to-noise ratio (SNR) in this PSD estimate, the dead time between strikes is minimized by cropping and concatenating the collected data about sections of the signal containing each impact and the resulting vibrations produced. As a result, the strikes appear at even intervals (approximately 0.2 seconds in length). The PSD is estimated for each accelerometer, using the same window length of 0.2 seconds.

Frequency bands in the PSD that preferably show a single peak for two accelerometers are initially considered for analysis. Each frequency band identified for modal analysis is selected for trending of average power levels based on the following criteria:

- The frequency band is preferably located in the upper frequency range to (a) avoid low frequency interferences transmitted through the floor and conduits; (b) accentuate the high frequency attenuation of a signal due to the accelerometers spacing.

- The frequency band shows high coherency (Eq. (7)) between accelerometers (i.e. the coherency is close to $1)$.

- If possible, the frequency band isolates a single peak in the PSD (no modal overlap).

- We can clearly observe the decrease in in-band power (Eq. (8)) across the array of accelerometers as the distance from the strike to the accelerometer increases.

- The frequency band contains sufficient damping to prevent overlap between decaying impulse responses.

\subsection{Detection: Envelope Power}

Detection refers to determining whether the vibrations propagating through the structure are characteristic of the presence of a faulty bearing. The process of detecting a faulty bearing is carried out at constant shaft rotational speed, once the system has reached steady state conditions. Thresholds are established for each accelerometer's envelope power signal, as a cap for healthy vibration signals. As a result, vibration levels exceeding the threshold would be indicative of a fault occurring within the system. In order to establish thresholds, each accelerometer's signal is demodulated by applying Hilbert filters about frequency bands satisfying the frequency band criteria and the envelopes are extracted for each set of data. For each accelerometer's demodulated signal, the envelope power is computed as an instantaneous power according to Eq. (12),

$$
{ }_{n}^{\left(m_{i}\right)}(\mathrm{t})=\frac{\left|\tilde{r}_{n}^{\left(m_{i}\right)}(t)\right|^{2}}{T_{s}},
$$

where $T_{s}$ is the sampling period. When thresholding the subscript healthy is introduced to the envelope power and envelope signals, i.e. $\quad{ }_{n, \text { healthy }}^{\left(m_{i}\right)}(t)$ and $\tilde{r}_{n, \text { heathy }}^{\left(m_{i}\right)}(t)$, to denote that the data used for thresholding is acquired while the system is operating under healthy operating conditions. The mean of each accelerometer's envelope power is computed and thresholds are set for each accelerometer's healthy envelope power such that inequality (13) holds.

$$
\stackrel{\left(m_{i}\right)}{n, \text { healthy }}(t)<T h r_{n}^{\left(m_{i}\right)} \underset{\left.n, m_{i}\right)}{-\left(m_{i}\right)}, \quad t
$$

$\underset{n, h e a t h y}{-\left(m_{i}\right)}$ is the mean value of the healthy envelope power for the isolated mode(s) of vibration $n$ and accelerometer $m_{i}$,

$$
\underset{n, \text { healthy }}{-\left(m_{i}\right)}=E\left[\frac{\left|\tilde{r}_{n, \text { healthy }}^{\left(m_{i}\right)}(t)\right|^{2}}{T_{s}}\right] .
$$

$T h_{n}^{\left(m_{i}\right)}$ is a constant chosen based on the accelerometer and mode(s) of vibration for the given envelope signal such that the healthy envelope power, when normalized with respect to the mean of the healthy envelope power, does not exceed this constant value for all time.

The constant $T h_{n}^{\left(m_{i}\right)}$ is also chosen such that inequality (13) is valid for the smallest value of $T h_{n}^{\left(m_{i}\right)}$ that allows for slight transients in the healthy vibrations envelope power, but vibrations due to any sort of defect, exceed the threshold

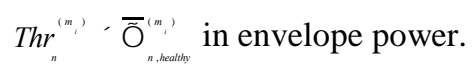

Once thresholds have been determined for each accelerometer and isolated mode(s) of vibration, each accelerometer's envelope power is plotted against its respective envelope power threshold for the isolated

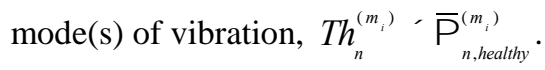

Envelope power levels that exceed the thresholds are averaged to obtain the average excess power level per time that exceeds the threshold for the accelerometer and mode(s) of vibration. This average envelope power level is denoted by $\underset{n, \text { exceed }}{-\left(m_{i}\right)}$. 


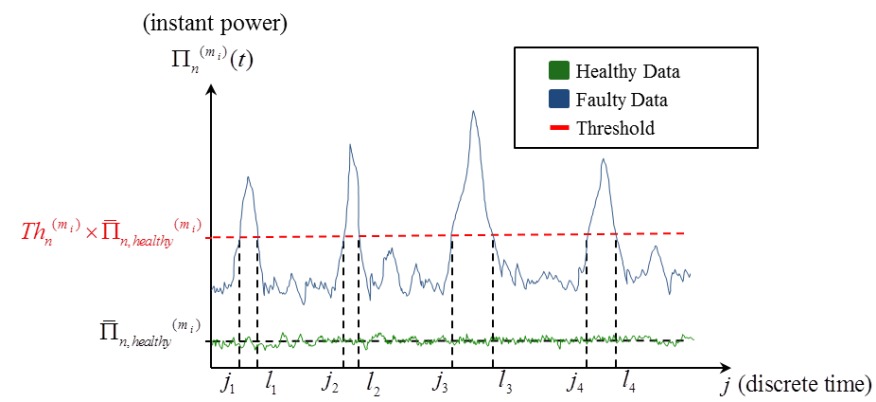

Figure 3. Zoomed in portion of an accelerometer's envelope power for mode of vibration $n$.

For the envelope power signals depicted in Figure 3, $\underset{n, \text { excee }}{-\left(m_{i}\right)}$ is defined according to Eq. (15)

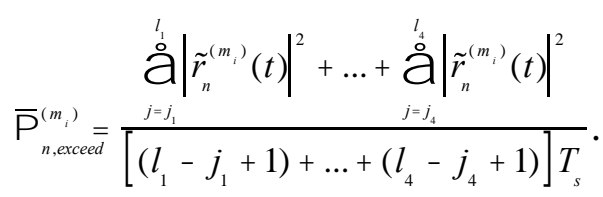

For each accelerometer's envelope power, if there is no fault occurring on the dynamometer, then $\underset{n \text {,exceed }}{-\left(m_{i}\right)}=0$ indicating that the system is healthy.

It is important to note that effective thresholds are established over some period of observation with the system operating under healthy operating conditions and once it has reached steady state conditions for a given shaft rotational speed. In order to avoid false alarms due to transients in the vibration signal resulting from impacts unrelated to mechanical failure (e.g., fish impacts) it is important to monitor the average envelope power level over multiple data sets. An alarm will be triggered assuming that the average envelope power is greater than zero for consecutive data sets.

\subsection{Detection: Trending}

In addition to thresholding the envelope power levels for detecting the presence of a fault, average power levels across predetermined frequency bands are trended to indicate a worsening condition:

1. The dynamometer is operated at various shaft rotational speeds. For each rotational speed, the power level within every predetermined frequency band is computed across the array of accelerometers, along with the confidence interval for each power level.

2. Each average power level is compared to its respective baseline average power level for the given shaft rotational speed.

3. Measurements are repeated over the course of weeks to determine whether the power levels across any of the frequency bands increases for any of the accelerometers over time.

4. If an upward trend in the power levels for any of the frequency bands appears across at least the majority of accelerometers and if the power levels approach or exceed an upper threshold, then there is a fault occurring (Figure 4).

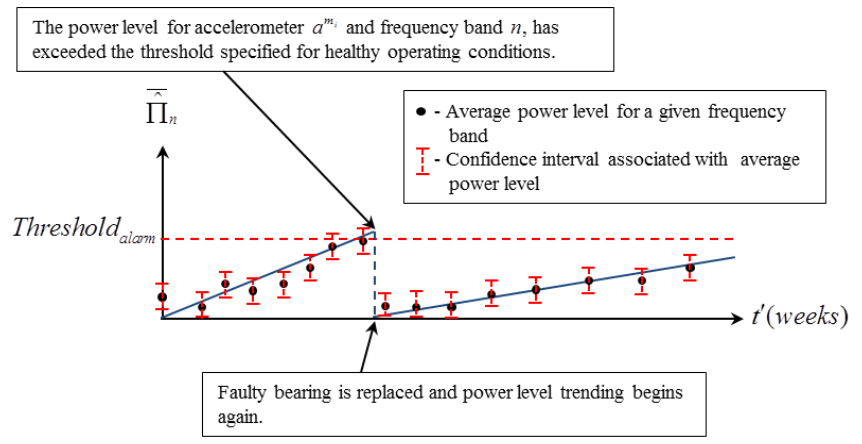

Figure 4. Trending of the average power levels over the course of weeks to detect presence of a faulty bearing.

\subsection{Localization}

Localization refers to determining the proximity of the faulty bearing location to the accelerometer placement (Figure 5). It is carried out at constant shaft rotational speed, under steady state conditions, and once the presence of a faulty bearing has been detected.

1. The power levels for specified frequency bands are computed for each accelerometer.

2. If an accelerometer acquires data with the highest power level within the frequency band and if for the same frequency band, the remaining accelerometers show a decrease in the power level as their distance increases, then this accelerometer is closest to the defect.

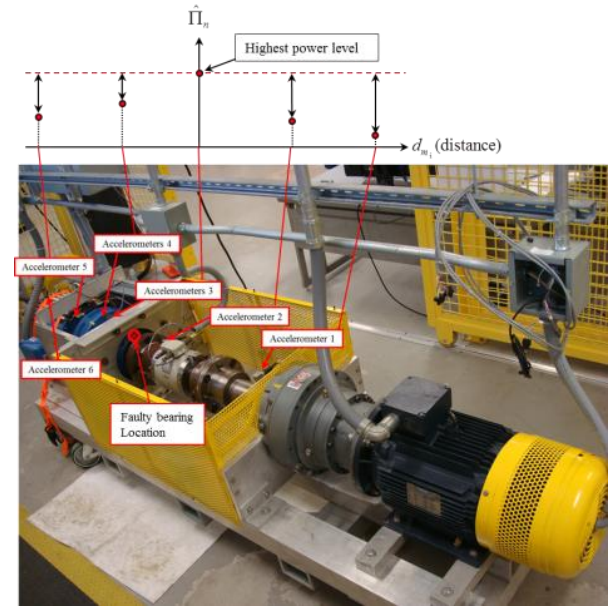

Figure 5. Localization of a faulty bearing based on comparing power levels for one frequency band and RPM across the array of accelerometers. 


\subsection{Identification}

Identification refers to determining the exact bearing containing the raceway defect. Again, the following procedure (also depicted in Figure 6) is performed under constant shaft rotational speeds, under steady state conditions, and once a faulty bearing has been detected:

1. Envelope analysis on the acquired vibration signals is performed within the specified frequency bands and across the array of accelerometers. From the envelope the period between impacts due to balls coming in contact with the defect is determined.

2. The period between impacts, denoted $T_{\text {impact }}$, should correspond to the Ball Pass Frequency for the inner raceway (BPFI) or outer raceway (BPFO) of one of the dynamometer's bearings (Randall \& Antoni, 2011).

These frequencies are defined as,

$$
\begin{gathered}
f_{o, b_{i}}=\frac{N_{B, b_{i}}}{2} f_{r}\left(1 \frac{D_{B, b_{i}} \cos \left(b_{b_{i}}\right)}{D_{P, b_{i}}}\right) \\
f_{i, b_{i}}=\frac{N_{B, b_{i}}}{2} f_{r}\left(1+\frac{D_{B, b_{i}} \cos \left(b_{i}\right)}{D_{P, b_{i}}}\right)
\end{gathered}
$$

$f_{o, b_{i}}$ is the impact frequency for an outer raceway defect (BPFO) in bearing $b_{i} . f_{i, b_{i}}$ is the impact frequency for an inner raceway defect (BPFI) in bearing $b_{i} \cdot N_{B, b}$ is the number of balls within the bearing. $f_{r}$ is the rotational speed (in $\mathrm{Hz}$ ) of the inner raceway, relative to the outer raceway. $D_{B, b_{i}}$ is the ball diameter. $D_{P, b_{i}}$ is the ball pitch diameter. $b_{i}$ is the ball contact angle (which is zero). The ball pitch diameter is calculated as,

$$
D_{P, b_{i}}=\left(\frac{I_{i, b_{i}}+I_{o, b_{i}}}{2}\right)
$$

$I_{i, b_{+}}$and $I_{o, b_{i}}$ are the maximum diameter of the inner race and maximum diameter of the outer race, respectively.

Although this paper focuses on detecting bearing raceway faults, application of this methodology to identify a bearing cage faults or ball defects, simply involves calculating the Fundamental Train Frequency (FTF) or Ball Spin Frequency (BSF) and comparing the impact frequency extracted from the analytic signal to these two values. Without providing any experimental evidence to validate the claim, the authors anticipate the application of this bearing fault detection technique to work for bearing cage faults and ball defects. However, experimental justification is left for future work.

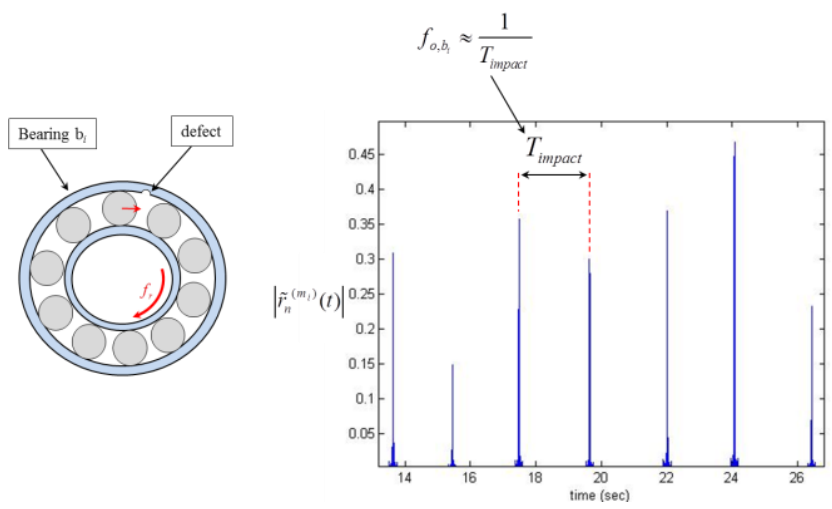

Figure 6. The period between subsequent impacts found from the modulus of the analytic signal formed by Hilbert filtering around a specified frequency band.

Equations 19 and 20 describe calculation of the FTF and BSF.

$$
\begin{gathered}
f_{C, b_{i}}=\frac{f_{r}}{2}\left(1 \frac{D_{B, b_{i}} \cos \left({ }_{b_{i}}\right)}{D_{P, b_{i}}}\right) . \\
f_{B S, b_{i}}=\frac{D_{P, b_{i}}}{2 D_{B, b_{i}}}\left\{1\left(\frac{D_{B, b_{i}} \cos \left({ }_{b_{i}}\right)}{D_{P, b_{i}}}\right)^{2}\right\} .
\end{gathered}
$$

$f_{C, b_{i}}$ is the impact frequency for a cage defect in bearing $b_{i}$ and $f_{B S, b_{i}}$ is the impact frequency for a ball defect within bearing $b_{i}$ (Randall \& Antoni, 2011).

The assumptions that are made for the methodology described in this section are as follows:

- The system is operating at a constant shaft rotational speed and there is minimal speed fluctuation.

- The system has reached steady state conditions.

- Thresholds for alarms are established while the system is operating void of any defects.

A flowchart describing the overall process of detection, localization, and identification of a bearing fault is provided in Figure 7.

\section{RESULTS}

In the first set of experimental results, effectiveness of the methods outlined in this thesis are demonstrated by detecting, localizing, and identifying a bearing with a raceway defect punched into its inner raceway. Each of the steps involved in the process outlined in this thesis are clearly demonstrated for straightforward application to the dynamometer. In Experiment II, data leading up to a yet to be determined fault occurring on the dynamometer was retroactively trended. Prior to currently ongoing 
maintenance on the dynamometer, it was possible to trend data previously acquired and observe an increase in average power levels for one of the frequency bands identified from studying the impulse response of the system.

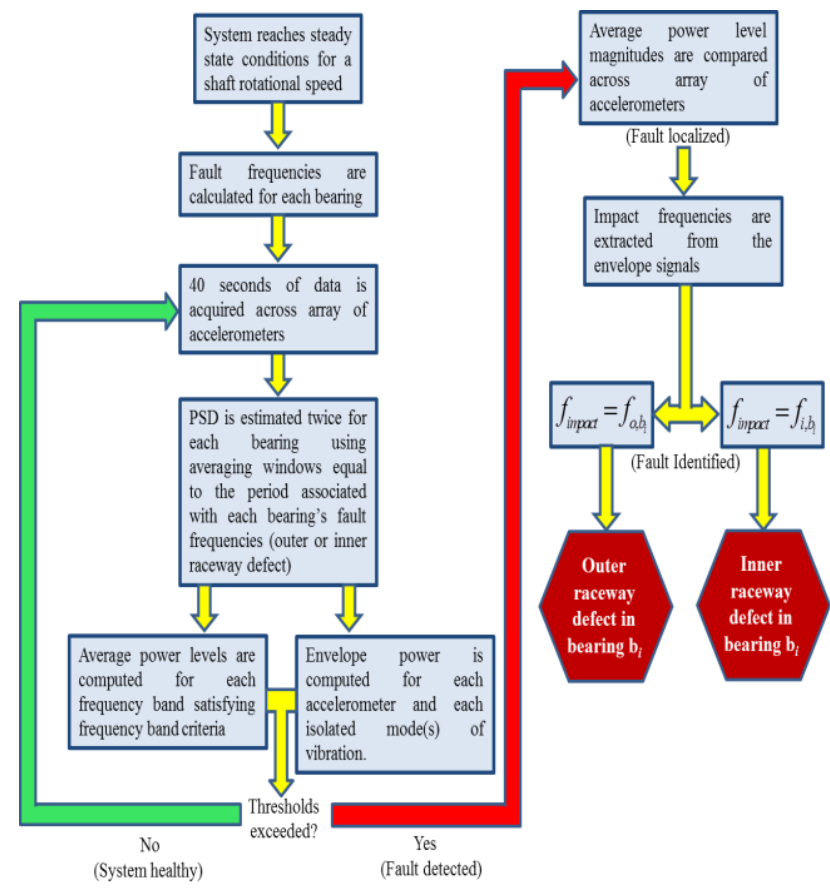

Figure 7. Bearing fault detection, localization, and identification flowchart.

\subsection{Experiment I: Controlled Lathe Setup}

A tachometer, as well as a plastic collar with an accelerometer fixed to its top surface that allowed for interchanging of bearings, were fixed to the shaft of the lathe (Figure 8). Four accelerometers were used to acquire vibrations along the length of the lathe. Accelerometers 1 to 3 were high frequency accelerometers with frequency responses ranging from 0.5 to $10,000 \mathrm{~Hz}$ (at $\pm 3 \mathrm{~dB}$ ), while accelerometer 4 was a low frequency accelerometer with a frequency response ranging from 0.2 to $3,000 \mathrm{~Hz}$ (at $\pm 3 \mathrm{~dB}$ ).

By collecting the vibrations across an array of accelerometers with a healthy bearing (void of known defects) in place, a baseline was established. A second identical bearing was carefully disassembled and had a defect punched into its inner raceway (referred to as the bad bearing). Due to the large manufacturer tolerances for the two bearings, even the healthy bearing produced a large amount of vibrations. In order to get a better idea of the background noise in the acquired signals for the healthy and bad bearings, a steel bearing (referred to as the ideal bearing) with much tighter manufacturer tolerances was mounted to the lathe and the vibrations were acquired along the array of accelerometers. The bearings used for the healthy and bad bearings in this experiment were stainless steel ball bearings with polymer ball cages, which allowed for simple disassembly with nothing more than hand pressure.

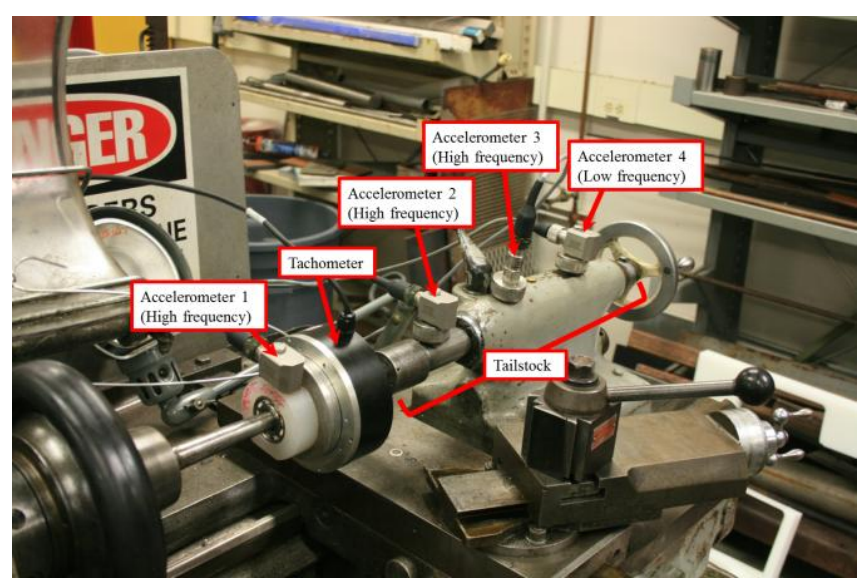

Figure 8. Lathe experimental setup.

The system was excited using calibrated hammer strikes administered next to accelerometer 1 and the impulse response for the system was studied (Figure 9).
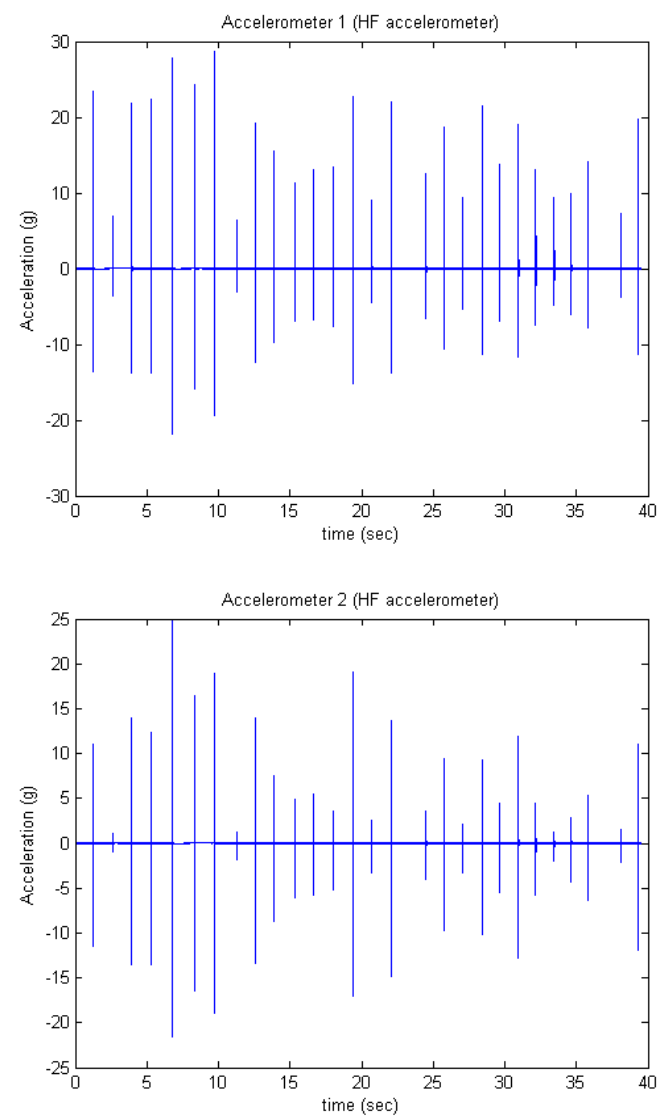

Figure 9. Time waveform of hammer impacts for accelerometers 1 (top) and 2 (bottom). 
Time windows of length 0.182 seconds (4096 points), were taken about each hammer impact to form the impacts signal for the PSD and coherency estimates (Figure 10). The frequency band $439-1126 \mathrm{~Hz}$, proved to have the steepest modal attenuation for the envelope with the most separation between impact vibrations and background noise.
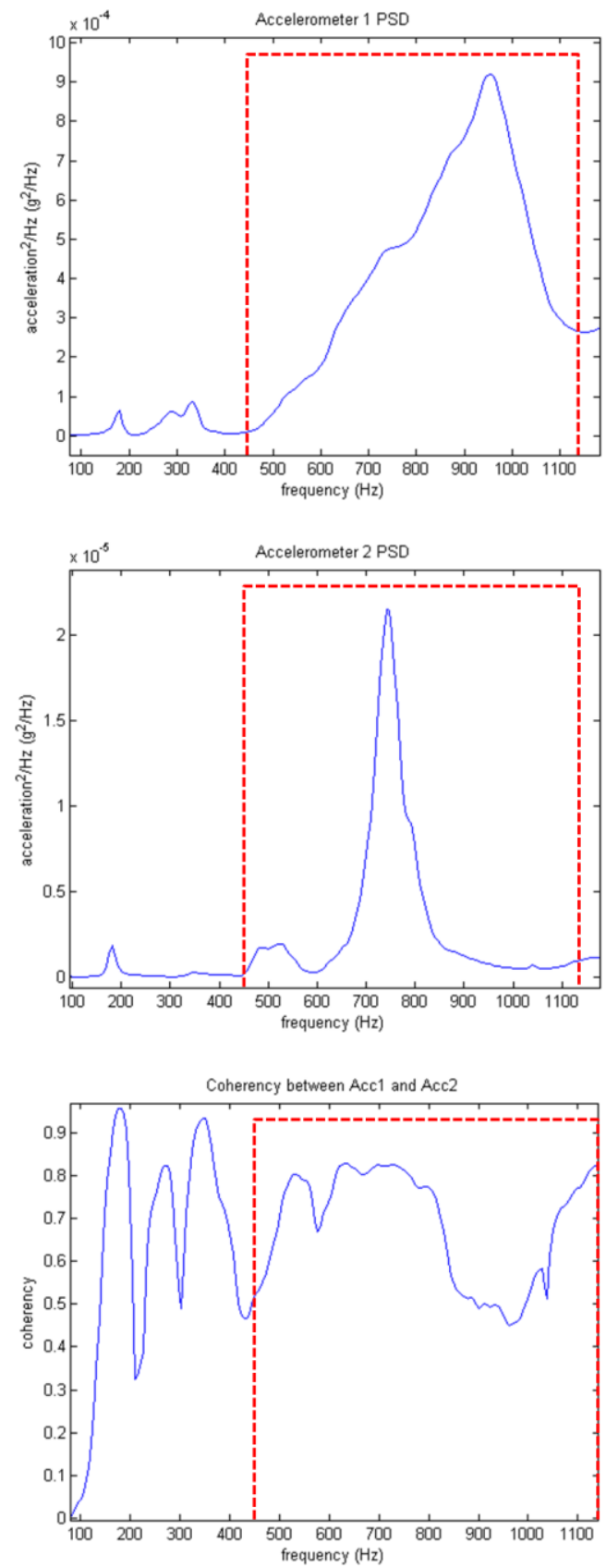

Figure 10. PSD for accelerometers 1 (top) and 2 (middle) and coherency between accelerometers 1 and 2 (bottom).

Following analysis of the PSD and coherency between accelerometers 1 and 2, the time waveform of the vibration signals was demodulated for the two accelerometers to check the modal decay for this frequency band (Figure 11).
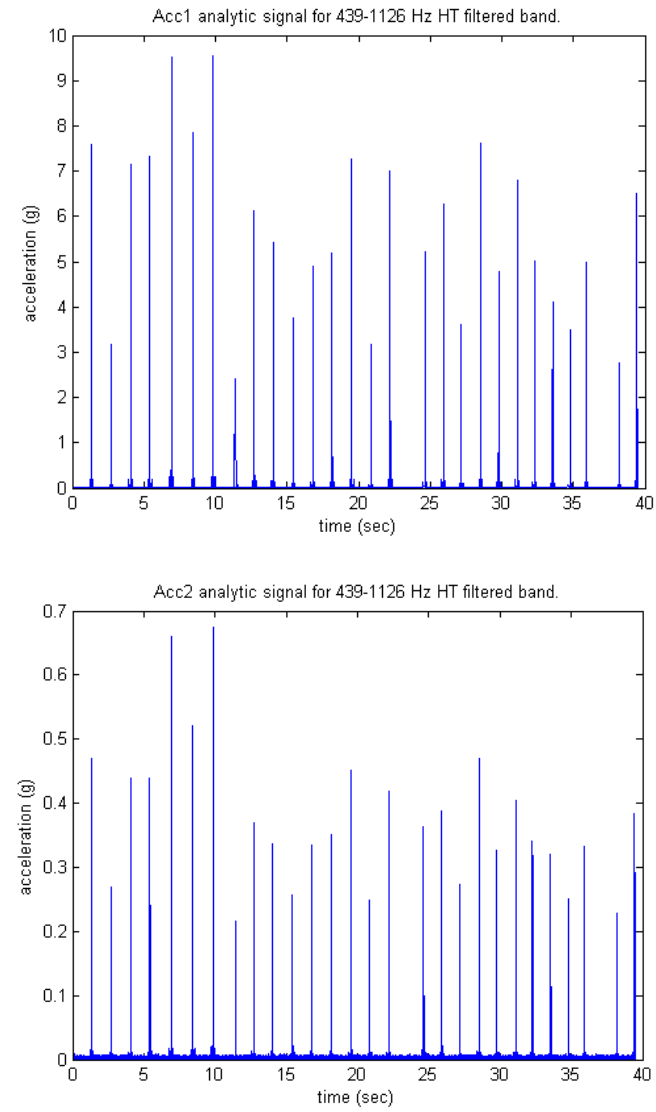

Figure 11. Demodulated signals for accelerometers 1 (top) and 2 (bottom) for the frequency band of 439-1126 Hz.

Following acquiring the vibrations across the array of accelerometers for the impulse response of the system, vibrations were collected for the healthy bearing, bad bearing, and the ideal bearing for a shaft rotational speed of 120 RPM (Figure 12). Data are sampled at a sampling rate of $22.5 \mathrm{kHz}$ and each set of processed data was of 39.5 seconds in length. An 8-pole low-pass filter was applied to the data with an edge frequency of $10 \mathrm{kHz}$.

With the healthy bearing in place, each accelerometer's envelope power was plotted for the Hilbert filtered frequency band of $439-1126 \mathrm{~Hz}$ and thresholds were set at Th $-\left(m_{i}\right)$

observed envelope power level. The constant $T h_{i}$ varied depending on the accelerometer and was selected such that the threshold was above the highest observed envelope power level for each accelerometer and this frequency band, as shown in Figure 13. 

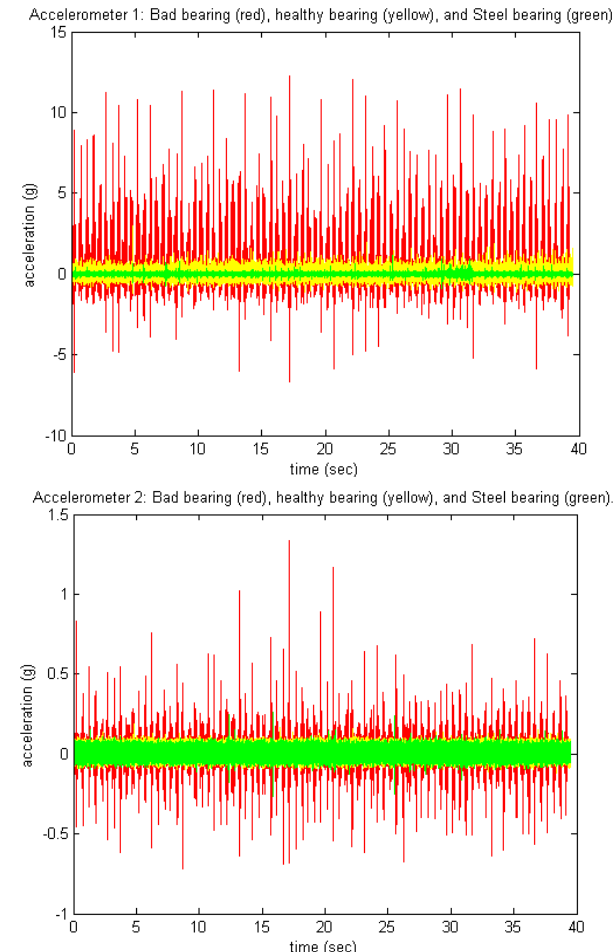

Figure 12. Time waveforms for the ideal bearing (green), healthy bearing (yellow), and bad bearing (red) for accelerometers 1 (top) and 2 (bottom).
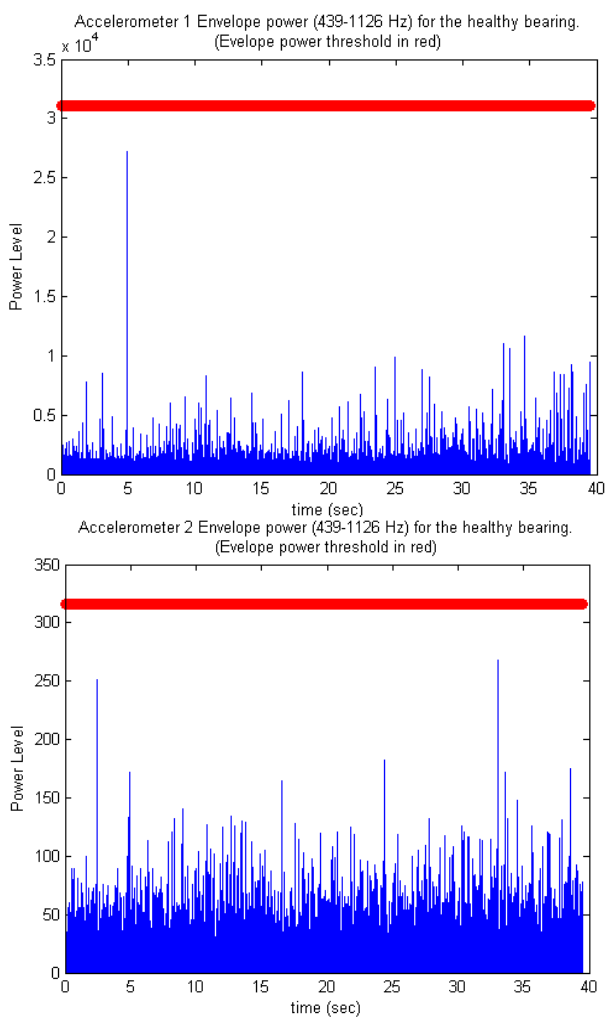

Figure 13. Envelope power and envelope power thresholds for accelerometers 1(top) and 2 (bottom) for the healthy bearing.
Data was then acquired from the bad bearing and the acquired vibration envelope power signals were plotted against their respective envelope power levels. Envelope power levels in excess can clearly be observed in Figure 14.
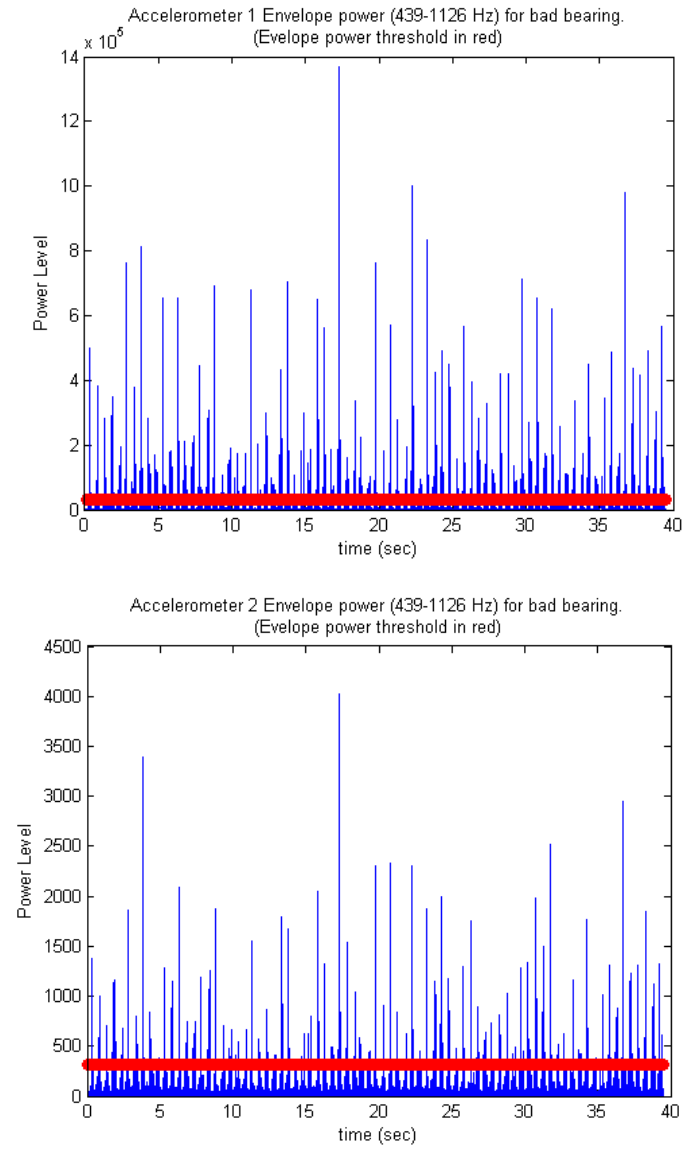

Figure 14. Envelope power levels acquired from the bad bearing for accelerometers 1 (top) and 2 (bottom).

The results of summing the excess envelope power levels across the array accelerometers for this demodulated frequency band are summed up in the Table 1 .

\begin{tabular}{|c|c|c|}
\hline $\begin{array}{l}\text { Accelerometer } \\
\text { number }\end{array}$ & $\begin{array}{c}\text { Threshold } \\
T_{h_{n}^{\left(m_{i}\right)} \quad-{ }_{\left(m_{i}\right)}}^{n}\left(g^{2} / \mathrm{sec}\right)\end{array}$ & $\begin{array}{c}\text { Excess } \\
\text { Average } \\
\text { Envelope } \\
\text { Power } \\
-\left(m_{t}\right) \\
n, \text { exceed } \\
\left(g^{2} / \mathrm{sec}\right)\end{array}$ \\
\hline 1 & $3.110 \times 10^{4}$ & $1.089 \times 10^{5}$ \\
\hline 2 & $3.159 \times 10^{2}$ & $6.663 \times 10^{2}$ \\
\hline
\end{tabular}

Table 1. Average envelope power levels and thresholds for bad bearing vibrations and accelerometers 1 and 2 . 
For the dynamometer, this would be the indication of the presence of a fault occurring in the system. As a further indicator of the presence of a fault occurring on the lathe, an increase in the average power level for this frequency band was observed across the array of accelerometers between the healthy bearing data set and the bad bearing data set.
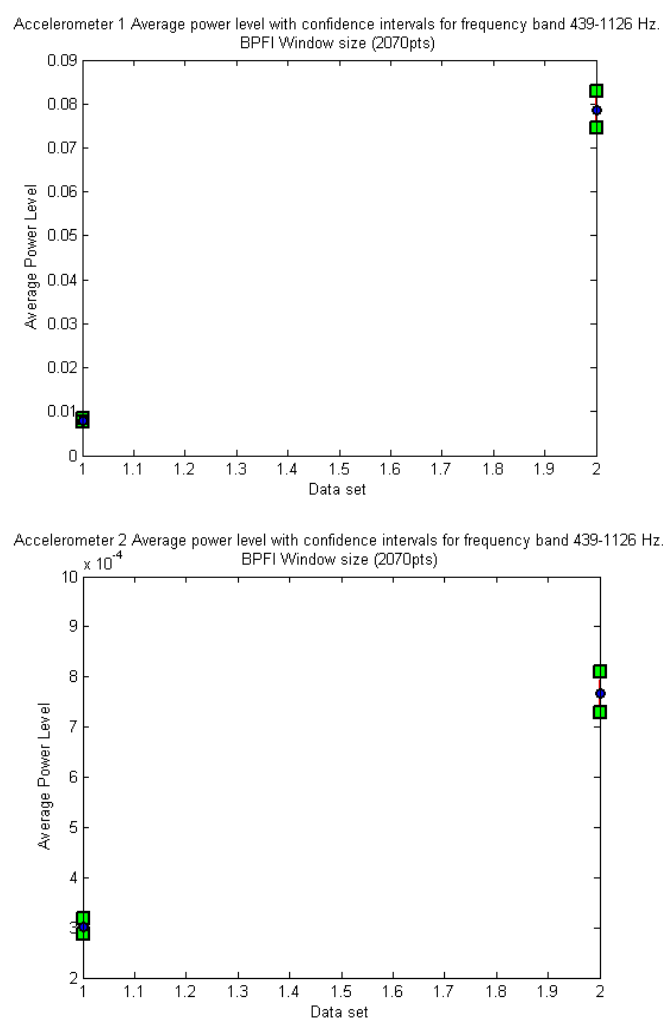

Figure 15. Average power levels across the frequency band of $439-1126 \mathrm{~Hz}$ for accelerometers 1 (top) and 2 (bottom).

The increase in average power levels are summed up in Table 2 .

\begin{tabular}{|c|c|}
\hline Accelerometer number & $\begin{array}{c}\text { Percent increase in average } \\
\text { power level for frequency } \\
\text { band 439-1126 Hz }\end{array}$ \\
\hline 1 & $876 \%$ \\
\hline 2 & $155 \%$ \\
\hline
\end{tabular}

Table 2. Increase in average power levels across the frequency band of 439-1126 Hz for accelerometers 1 and 2 .

Having detected the presence of a defect occurring on the lathe, the next step was to localize this defect with respect to the accelerometer placement. By plotting the increase in average power levels across the array of accelerometers in a single figure, localization of the fault to the position of accelerometer 1 becomes apparent. The average power levels across the frequency band $439-1126 \mathrm{~Hz}$ for the faulty bearing data, along with their respective confidence intervals are shown in Figure 16.

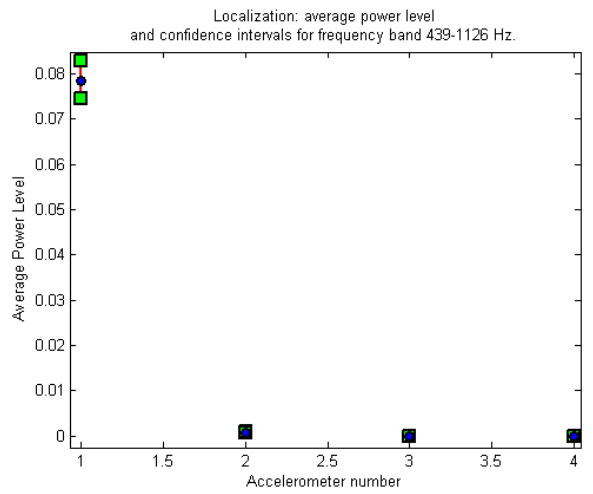

Figure 16. Average power levels with confidence intervals for faulty bearing data and frequency band $439-1126 \mathrm{~Hz}$ for accelerometers 1-4.

Accelerometer 1 showed the highest average power level for this frequency band, with accelerometers 2-4 showing a downward trend in power levels for this frequency band as their distance from accelerometer 1 increased. Without prior knowledge of the placement of the faulty bearing, Table 2 and Figure 16 make it apparent that the position of the faulty bearing was closest to the placement of accelerometer 1 . Thus, by comparing the average power levels across the array of accelerometers for a given frequency band, it was possible to localize the position of the faulty bearing with respect to the accelerometer placement to the position of accelerometer 1 .

Having detected the presence of a defect and localized its position with respect to the accelerometer placement, the next step was to identify the exact bearing and raceway the defect corresponded to. From the envelope for accelerometer 1 (Figure 17), the average period between impacts was found to be 0.0914 seconds which corresponds to an impact frequency of $10.94 \mathrm{~Hz}$.

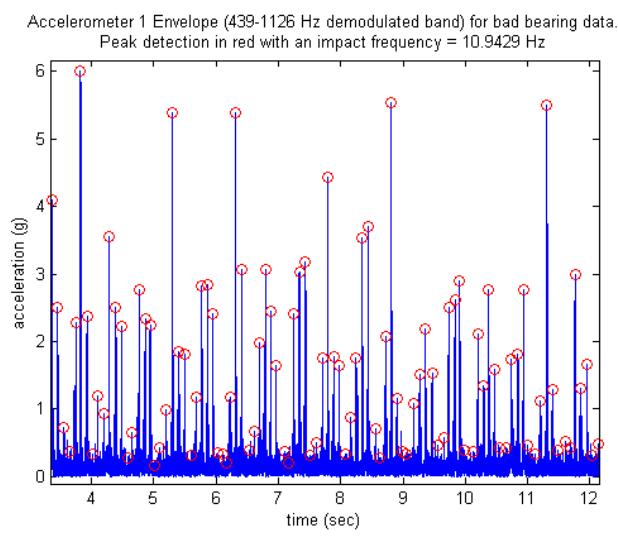

Figure 17. Envelope for bad bearing data acquired by accelerometer 1 for with demodulation about the frequency band of $439-1126 \mathrm{~Hz}$. 
The theoretical fault frequency for an inner raceway defect within the bearing used for the experiment and for a shaft rotational speed of $120 \mathrm{RPM}$ was $10.86 \mathrm{~Hz}$. Thus, the defect was identified as an inner raceway defect with $0.74 \%$ error.

\subsection{Experiment II: Trending Data Leading to Fault on the Dynamometer}

The approach of detecting, localizing, identifying bearings with raceway defects is illustrated through the analysis of a series of experimental data collected over the course of a month leading up to a fault in the dynamometer. By retroactively trending the data leading to the near-failure of one of the electric motors in the dynamometer, a positive trend in energy levels for a specific frequency band was observed, which was present across the array of accelerometers and two bearings were identified as possible sources of the fault. Shortly before the electric motor was dismounted, excessive vibrations and sound radiation were observed. The fault was then localized via a calibrated stethoscope to the location of two of the dynamometer's bearings.

Data collected over the course of a month were processed for accelerometers 3 and 5 (Figure 18) before the dynamometer was disassembled and the electric motor was sent for maintenance and repair.

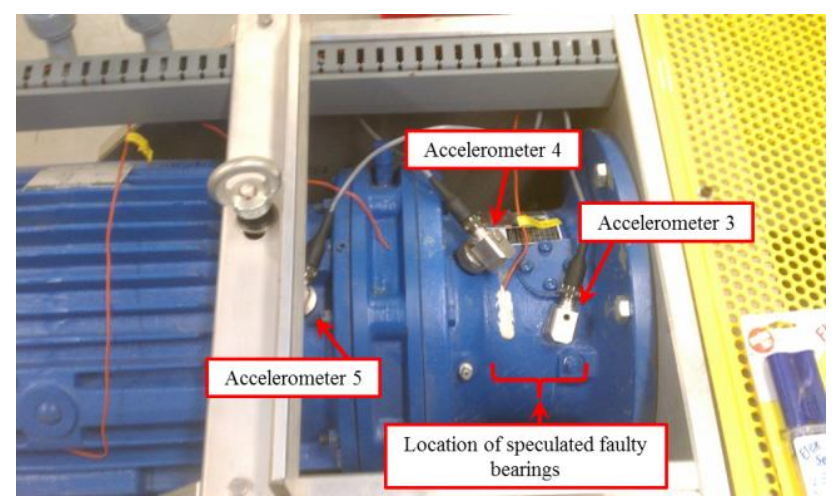

Figure 18. Accelerometer placement on the dynamometer and the location of the speculated faulty bearings.

The impulse response of the dynamometer was studied and the frequency band of $278-463 \mathrm{~Hz}$ was identified as satisfying the frequency band criteria (section 4.1). In processing the data collected prior to detecting the fault, an upward trend in the average power across the frequency band of 278-463 Hz was observed (Figure 19).

Within the 278-463 $\mathrm{Hz}$ band, the data acquired by accelerometer 3 showed an increase in averaged power level of approximately $297 \%$ in four weeks, while accelerometer 5 showed an increase of approximately $321 \%$ over the same time period. Given the confidence intervals shown in Figure 19, these increases in power level are very significant and clearly indicate a change in the structural response of the dynamometer.
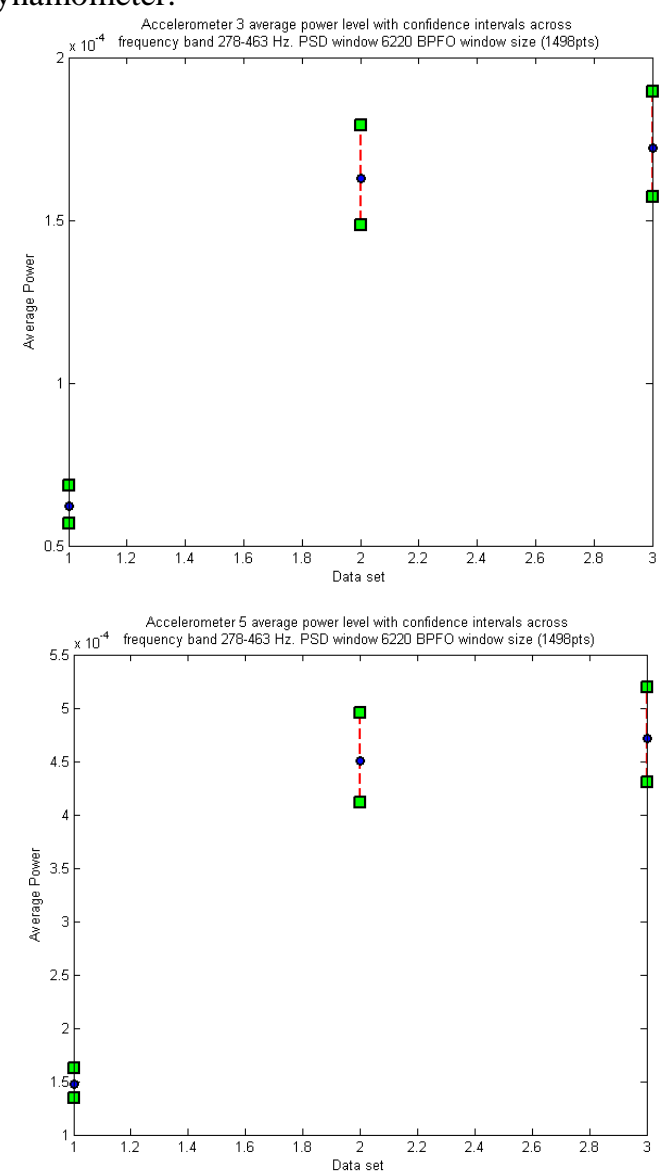

Figure 19. Average power levels across the frequency band of $278-463 \mathrm{~Hz}$ for accelerometers 3 (top) and 5 (bottom).

The signal acquired by accelerometer 3 on the last day was then demodulated about the same frequency band of 278$463 \mathrm{~Hz}$ (Figure 20) and a periodic impact was noticed from the envelope. The period between impacts was determined to be 0.2761 seconds, which corresponds to an impact frequency of approximately $3.62 \mathrm{~Hz}$ and closely matches the impact frequency for the two motor bearings located at position of accelerometer 3 (Figure 18).

Indeed, for a shaft rotational speed of 50 RPM, one bearing would theoretically produce vibrations at an impact frequency of $3.41 \mathrm{~Hz}$ (outer raceway defect), while the second bearing would produce vibrations with an impact frequency of $3.8 \mathrm{~Hz}$ (outer raceway defect). This is very close to the impact frequency caused by a defect on the outer raceway of two specific bearings. This periodicity in the vibration signal was only observed in the data acquired by accelerometer 3 which also indicated that one of the two bearings in question contained a defect, since accelerometer 3 was placed directly over the speculated fault location (Figure 18). 
The maintenance on the dynamometer confirmed the measurements. The two faulty bearings have since been replaced.

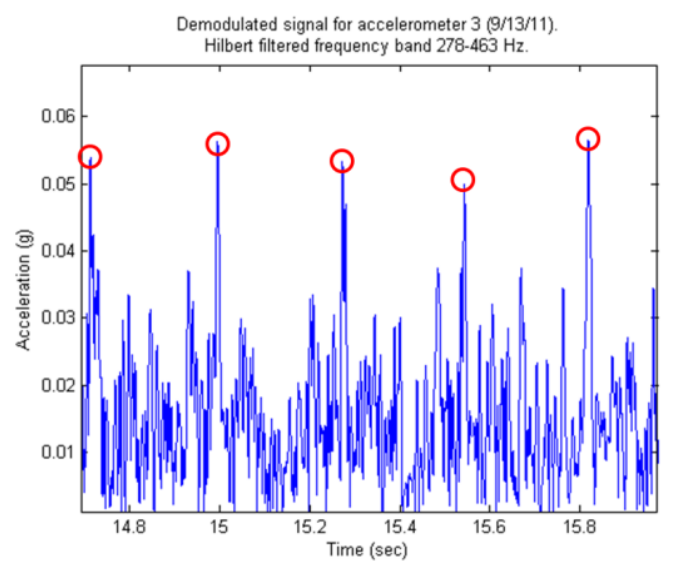

Figure 20. Envelope for data acquired by accelerometer 3 from last day of data acquisition.

\section{CONCLUSION}

In this paper, a method of using an array of accelerometer to detect the presence of bearing with a raceway defect, localize its position with respect to the placement of accelerometers, and identifying the exact bearing and raceway to which the defect corresponds to has been presented. The methodology outlined in this paper is described for application to an ocean turbine dynamometer, but is applicable to any rotating machinery containing bearings.

The method outlined in this paper was carried out on a lathe with a faulty bearing in order to demonstrate implementation on a more ideal system, for straight forward application to the more complex system, such as the dynamometer. Following detecting the presence of the defect, its position on the lathe was localized with respect to the accelerometer placement. Lastly, the faulty bearing was identified, in addition to the raceway the defect corresponded to (inner raceway), with $0.74 \%$ error.

Next, the process of analyzing vibrations across an array of accelerometers in order to specifically target bearing raceway defects occurring on a dynamometer was demonstrated. Through trending of the average power within across a specific frequency band satisfying the frequency band criteria, a growing defect occurring in the dynamometer was detected. Following this, the defect was localized relative to the accelerometer placement by comparing the average power levels for the same frequency band across the array of accelerometers. In addition, an envelope analysis within this frequency band showed periodic impacts, whose frequency of occurrence closely matched the impact frequency (outer raceway) for two of the motor bearings. The fault was also localized via a calibrated stethoscope: this test supports the conclusions obtained with the approach presented in this paper.

\section{ACKNOWLEDGEMENT}

This research was funded by the Southeast National Marine Renewable Energy Center (SNMREC) at Florida Atlantic University.

\section{REFERENCES}

Fernandez, A., Bibao, J., Bediaga, I., Gaston, A., \& Hernandez, J., (2005). Feasibility study on diagnostic methods for detection of bearing faults at an early stage. Proceeding of WSEAS International Conference, November 2-4, Venice, Italy, pp.113-118. http://www.wseas.us/elibrary/conferences/2005venice/p apers/508-367.pdf

Muszynska, A., (1995). Vibrational Diagnostics of Rotating Machinery Malfunctions. International Journal of Rotating Machinery, vol. 1, No. 3-4, pp. 237-266. doi:10.1155/S1023621X95000108

International Standards Organization (ISO) (2002). Condition monitoring and diagnostics of machinesVibration condition monitoring part 1: General Procedures. In ISO 13373-1: 2002.

International Standards Organization (ISO) (2005). Condition monitoring and diagnostics of machinesVibration condition monitoring part 2: Processing, analysis and presentation of vibration data. In ISO 13373-2: 2005.

Ho, D., \& Randall, R. B., (2000). Optimisation of Bearing Diagnostic Techniques Using Simulated and Actual Bearing Fault Signatures. Journal of Mechanical Systems and Signal Processing, vol. 14, Issue 5, pp. 763-788. doi: 10.1006/mssp.2000.1304

Ifeachor, E. C., \& Jervis, B. W., (2002). Spectrum estimation and analysis. In Digital Signal Processing 2nd ed (pp. 704-705). Harlow, England: Pearson Education Limited.

Driscoll, F. R., Alsenas, G. M., Beaujean, P. P., Ravenna, S., Raveling, J., Busold, E., \& Slezycki, C. (2008). A $20 \mathrm{~kW}$ Open Ocean Current Test Turbine. Proceedings of the MTS/IEEE Oceans '08. September. Quebec City, Quebec, Canada. http://209-20-8491.slicehost.net/assets/2009/3/4/A_20_kW_Open_Ocea n_Current_Test_Turbine.pdf

Marichal, G. N., Arte' s, M., \& García-Prada, J. C., (2010) An intelligent system for faulty-bearing detection based on vibration spectra. Journal of Vibration and Control, vol. 17, no. 6, pp. 931-942. doi: 10.1177/1077546310366264

Cooper, G. R., \& McGillem, C. D., (1999). Spectral Density. In Probabilistic Methods of Signal and System Analysis 3rd ed. (pp. 257-271). Oxford, New York: Oxford University Press, Inc. 
Konstantin-Hansen, H., \& Herlufsen, H., (2003). Envelope Analysis for Diagnostics of Local Faults in Rolling Element Bearings. Bruel \& Kjaer Sound and Vibration Measurement, pp.

http://www.bksv.com/doc/bo0501.pdf

Konstantin-Hansen, H., \& Herlufsen, H., (2010). Envelope and Cepstrum Analysis for Machinery Fault Identification. Bruel \& Kjaer Sound and Vibration, pp. 10-12. http://www.sandv.com/downloads/1005hans.pdf

Onel, I. Y., Dalci, K. B., \& Senol, I., (2005). Detection of Outer Raceway Bearing Defects in Small Induction Motors Using Stator Current Analysis. Sadhana, vol. 30, part 6, pp.716. doi: 10.1007/BF02716705

Courrech, J., \& Gaudet, M.,. Envelope Analysis - The Key to Rolling-Element Bearing Diagnosis. Bruel \& Kjaer Vibration and Sound. http://www.bksv.com/doc/BO0187.pdf

Renwick, J. T., \& Babson, P. E., (1985). Vibration Analysis-A Proven Technique as a Predictive Maintenance Tool. IEEE Transactions on Industry Applications, vol. IA- 21, no. 2. doi: 10.1109/TIA.1985.349652

Mjit, M. M., (2009). Methodology For Fault Detection and Diagnostics in an Ocean Turbine Using Vibration Analysis and Modeling. Master's thesis, Florida Alantic University, Boca Raton, FL. http://snmrec.fau.edu/sites/default/files/research/theses/ DT-09-335.pdf

Mjit, M., Beaujean, P. J., \& Vendittis, D. J., (2011). Comparison of Fault Detection Techniques for an Ocean Turbine. Annual Conference of the Prognostics and Health Management Society. September 25-29, Portland,

OR. https://www.phmsociety.org/sites/phmsociety.org/files/ phm_submission/2011/phmc_11_023.pdf

Mjit, M., Beaujean, P. J., \& Vendittis, D. J., (2010). Remote Health Monitoring for Offshore Machines, using Fully Automated Vibration Monitoring and Diagnostics. Proceedings of Annual Conference of the Prognostics and Health Management Society, October 10-16, Portland,

OR. https://www.phmsociety.org/sites/phmsociety.org/files/ phm_submission/2010/phmc_10_006.pdf

Norton, M. P., \& Karczub, D. G., (2003). The Analysis of Noise and Vibration Signals. In, Fundamentals of noise and vibration analysis for engineers, 2 nd ed. (pp. 353357). Cambridge, UK: Cambridge University Press.

Valente, M., et al. (2008). Hearing Protection. In, Audiology Treatement, 2nd ed. (pp. 371-373). New York, NY: Theime Medical Publishers.

Thrane, N., Wismer, J., Konstantin-Hansen, H., \& Gade, S., (1995) Practical use of the "Hilbert transform", Bruel \& Kjaer Application Notes. http://www.bksv.com/doc/bo0437.pdf
Thrane, N., (1984). The Hilbert Transform. Bruel \& Kjaer, Techical Review, No. 3 (pp. 3-15). http://www.bksv.com/doc/bv0015.pdf

McFadden, P. D., \& Smith, J. D., (1984). Model for the Vibration Produced by a Single Point Defect in a Rolling Element bearing. Journal of Sound and Vibration, vol. 96, no. 1, pp. 69-82. doi: 10.1016/0022460X(84)90595-9

Jayaswal, P., Wadhwani, A. K., \& Mulchandani, K. B., (2008). Machine Fault Signature Analysis. International Journal of Rotating Machinery. vol. 2008. doi:10.1155/2008/583982

McInerny, S. A., and Dai, Y., (2003). Basic Vibration Signal Processing for Bearing Fault Detection. IEEE Transactions on Education, vol. 46, no. 1. doi: 10.1109/TE.2002.808234

Wang, W.-Y., \& Harrap, M. J., (1996). Condition Monitoring of Ball Bearings Using Envelope Autocorrelation Technique. Journal of Machine Vibration, vol. 5, pp. 34- 44. http://cat.inist.fr/?aModele $=$ afficheN\&cpsidt $=3150743$

Wang, Y.-F., \& Kootsookos, P. J., (1999). Modeling of Low Shaft Speed Bearing Faults For Condition Monitoring. Mechanical Systems and Signal Processing, vol. 12, no. 3, pp. 415-426. http://espace.library.uq.edu.au/eserv.php?pid=UQ:1096 8\&dsID=MechSysAndSigPro.pdf

Sheen, Y. -T., (2004). A complex filter for vibration signal demodulation in bearing defect diagnosis. Journal of Sound and Vibration, vol. 276, pp.105-119. doi: 10.1016/j.jsv.2003.08.007

Sheen, Y.-T., (2007). An impulse-response extracting method from the modulated signal in a roller bearing. Journal of the International Measurement Confederation, vol. 40, Issue 9-10, pp. 868-875. http://ir.lib.stut.edu.tw/bitstream/987654321/8162/2/pap er4.pdf

Su, Y.-T., \& Lin, S.-J., (1992). On Initial Fault Detection of a Tapered Roller Bearing: Frequency Domain Analysis. Journal of Sound and Vibration, vol. 155, no. 1, pp. 7584. doi: 10.1016/0022-460X(92)90646-F

\section{BIOGRAPHIES}

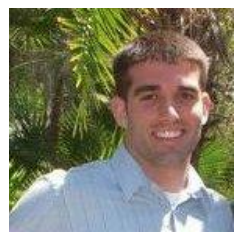

Nicholas C. Waters earned his bachelor's degree from the University of California, Davis in Applied Mathematics. In 2012, he received his master's degree from Florida Atlantic University in Ocean Engineering under the advisement of Dr. Pierre-Philippe Beaujean. His graduate career field of study was focused on machine condition monitoring and its application to an ocean turbine. Nicholas is an active member of the Institute of Electrical and Electronic Engineers (IEEE) and the Marine Technology Society (MTS). 


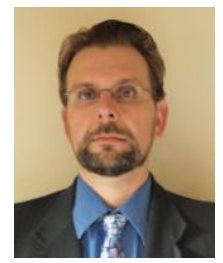

Pierre-Philippe J. Beaujean received the $\mathrm{Ph} . \mathrm{D}$. degree in ocean engineering from Florida Atlantic University in 2001. He is an Associate Professor at the Department of Ocean and Mechanical Engineering, Florida Atlantic University. He specializes in the field of underwater acoustics, signal processing, sonar design, data analysis, machine health monitoring, and vibrations control. Dr. Beaujean is an active member of the Acoustical Society of America (ASA), the Institute of Electrical and Electronic Engineers (IEEE) and the Marine Technology Society (MTS).

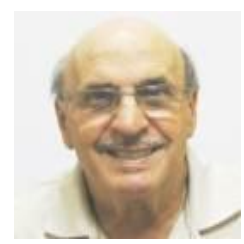

Dr. David J. Vendittis [Ph.D. (Physics) - American University, 1973] is a Research Professor (part time) at the Department of Ocean and Mechanical Engineering, Florida Atlantic University. Additionally, he is the Technical Advisory Group (ASA/S2) chairman for an International Standards Organization subcommittee, ISO/TC108/SC5 Machinery Monitoring for Diagnostics. This committee writes international standards that support Machinery Condition Monitoring for Diagnostics. He was appointed to this position by the Acoustical Society of America (ASA) 